\title{
BULLETIN Bulletin hispanique
}

HISPANIQUE Université Michel de Montaigne Bordeaux

109-1 | 2007

Varia

La

ventana

indiscreta

Cronotopo y teoría de la autobiografía

Ricardo Fernández

(2) OpenEdition

Journals

Edición electrónica

URL: http://journals.openedition.org/bulletinhispanique/143

DOI: 10.4000/bulletinhispanique. 143

ISSN: 1775-3821

Editor

Presses universitaires de Bordeaux

Edición impresa

Fecha de publicación: 1 junio 2007

ISBN: 978-2-85276-094-3

ISSN: 0007-4640

Referencia electrónica

Ricardo Fernández, «La ventana indiscreta », Bulletin hispanique [En línea], 109-1 | 2007, Publicado el

26 diciembre 2013, consultado el 01 mayo 2019. URL : http://journals.openedition.org/

bulletinhispanique/143 ; DOI : 10.4000/bulletinhispanique.143

Tous droits réservés 


\title{
La ventana indiscreta: cronotopo y teoría de la autobiografía
}

\author{
Ricardo FERnÁNDEZ \\ University of St Andrews - UK
}

Cet article étudie la présence de l'image des fenêtres dans la littérature autobiographique espagnole contemporaine à travers l'analyse de quatre autobiographies: Ramón de Mesonero Romanos, Memorias de un setentón (1880); Rafael Alberti, La arboleda perdida (1942); Luis Cernuda, Ocnos (1942); Carmen Martín Gaite, El cuarto de atrás (1978). On prend l'image de la fenêtre comme un ensemble de stratégies littéraires qui sont considérées comme métaphore et comme modèle résumant les stratégies des oeuvres autobiographiques. Ainsi, la fenêtre est l'emblème que nous proposons comme théorie de l'autobiographie, considérée d'un point de vue performatif et moral.

Este artículo estudia la presencia de la imagen de la ventana en la literatura autobiográfica española contemporánea a través del análisis de cuatro autobiografías: Ramón de Mesonero Romanos, Memorias de un setentón (1880); Rafael Alberti, La arboleda perdida, 1 (1942); Luis Cernuda, Ocnos (1942); Carmen Martín Gaite, El cuarto de atrás (1978). La imagen de la ventana supone un conjunto de operaciones y estrategias literarias que son estudiadas en tanto que metáfora y modelo que concentra en si el conjunto de estrategias literarias de la escritura autobiográfica en que se inserta. De este modo, la ventana se ofrece como emblema de una teoría de la autobiografía a partir de la consideración ética y performativa de la misma.

This article studies the presence of the image of windows in the autobiographical literature of contemporary Spanish through the analysis of four autobiographies: Ramón de Mesonero Romanos, Memorias de un setentón (1880); Rafael Alberti, La arboleda perdida, 1 (1942); Luis Cernuda, Ocnos (1942); Carmen Martín Gaite, El cuarto de atrás (1978). The image of the window is taken as a set of literary strategies that are

$B H i$, Tome 109, nº 1 - juin 2007 - p. 187 à 204. 
considered as a metaphor and a model that summarizes the strategies of autobiographical writing. In this way, the window is the emblem that we propose for a theory of the autobiography, from an ethical and performative point of view.

Mots-clés : Fenêtre - Autobiographie - Masque - Fantôme - Théâtre.

Carmen Martín Gaite llamó una vez la atención sobre la reiterada a la ventana. Ventaneras, las llamaba ${ }^{1}$, recogiendo esa palabra del siglo de oro para dotarla de un mejor sentido que el peyorativo original. No le faltaba razón, por supuesto, pero ventaneras y ventaneros, además, los ha habido en otras lenguas y culturas, y por supuesto que en otras manifestaciones artísticas, especialmente la pintura: desde los interiores de Vermeer de Delft ("Joven leyendo una carta frente a una ventana abierta», 1657) hasta Rafols Casamada ("Agosto», 1998), pasando, por ejemplo, por «Persona asomada a la ventana» (1925), de Salvador Dalí, en el que aparece vista de espaldas su hermana Ana María contemplando a través de la ventana abierta el ensoñador paisaje de la bahía de Cadaqués.

El terreno autobiográfico no es una excepción, de modo que no resultaría difícil elaborar un catálogo de ventaneros y ventaneras desde los inicios de la autobiografía moderna en España hasta hoy. Sin embargo, si bien traeremos a estas páginas algunos de ellos y de ellas, resultará mucho más interesante aventurarse en las posibles razones para que la ventana tenga en la escritura autobiográfica un valor propio. La elección de ejemplos españoles no es sino un intento de constatar en el terreno de la literatura autobiográfica española, una vez más, la validez de una exploración teórica e histórica que homologaría nuestra escritura autobiográfica a la de otros ámbitos culturales occidentales.

Esa fascinación por la ventana bien tiene que ver con esta afirmación de Andrew Kaplan: «The window can coordinate the external world of places with the internal world of thought and feeling» ${ }^{2}$. Precisamente, la joven del cuadro de Vermeer puede ilustrar esas palabras, en cuanto parece establecerse una estrecha relación entre la lectura de la carta y la ventana abierta, no sólo porque la joven lee a la luz que a través de la ventana penetra en el interior,

1. Véase C. Martín Gaite, Desde la ventana. Enfoque femenino de la literatura española, Madrid, Espasa-Calpe, 1987.

2. A. Kaplan, "Windows: a meditation on modernity», Word \& Image, 18. 2, AprilJune: 2002, p. 162. 
sino porque, precisamente, por esa luz que permite la lectura, la ventana repite en eco la apertura psicológica a lo "otro» que debe producirse en el acto lector de la joven. Y ese "otro" es el mundo de donde viene la luz dorada, pero también el mundo de la imaginación, de la fabulación, de lo inesperado que sugieren la intangibilidad de la luz y de un mundo exterior que existe para nosotros, espectadores del cuadro, sólo como una posibilidad indefinida, multiforme. Quizá sea así también para ella, que sin mirar la ventana recibe en su cuerpo la luz que por aquella atraviesa.

En la autobiografía la ventana actúa de forma similar, a diversos niveles, en relación profunda con la lectura, particularmente en tanto se pueda entender la escritura autobiográfica como una escritura y una lectura del propio pasado. Así, la ventana actúa como un mecanismo que recoge en el juego que da en el texto el juego que plantea la autobiografía en sus diferentes niveles: por un lado como trabajo de la memoria sobre el propio pasado al que se asoma el autobiógrafo y, por otro, como respuesta ética ${ }^{3}, o$ como performance ${ }^{4}$ ante y para el otro.

La ventana es, por tanto, algo más que el recuerdo de una ventana, incluso cuando precisamente por ser el marco de un recuerdo se la trae a colación en el discurso autobiográfico. En este sentido, no es tanto como indicio de una forma histórica de experimentar el mundo como estudiamos la ventana, sino como el conjunto de estrategias literarias que trascienden e incluyen esa experiencia y la sitúan en el marco de las posibilidades de una vía artística para la exploración de la propia identidad. Veamos ahora nuestro primer ejemplo de escritura autobiográfica al borde de la ventana. Se trata de las Memorias de un setentón, natural y vecino de Madrid (1880), de Ramón de Mesonero Romanos.

Fernando Durán López precisa las coordenadas de la escritura autobiográfica de Mesonero en estas Memorias:

Los inmediatos modelos de que dispuso Mesonero dibujan, por tanto, una clara línea hacia una mayor integración del punto de vista personal de la memoria subjetiva con una visión

3. Véase A. G. Loureiro, The Ethics of Autobiography. Replacing the Subject in Modern Spain, Nashville, Vanderbilt University Press, 2000.

4. Véase J. M. Pozuelo Yvancos, «Autobiografía: del tropo al acto de lenguaje». Autobiografia en España: un balance, eds. Celia Fernández Prieto, María Ángeles Hermosilla Álvarez, Madrid, Visor Libros, 2004, 159-172. 
histórico-costumbrista que represente, más que una vida particular, una experiencia colectiva. El proceso culmina de forma lógica en las Memorias de un setentón 5 .

Para la articulación de esa doble línea entre la memoria de la Historia y la memoria de lo privado encuentra Mesonero en el uso de ventanas y balcones una herramienta apropiada. Podemos mostrarlo en las primeras páginas, a partir del relato que se hace en ellas de las jornadas previas al levantamiento del pueblo de Madrid contra las tropas napoleónicas el mes de mayo de 1808. Mesonero se muestra como testigo presencial de estos hechos; pero Mesonero Romanos es en 1808 el niño Ramón. Este punto de partida se convierte en una paradójica posición difícil de resolver dentro de los parámetros de la escritura autobiográfica de la época, historicista, testimonial. Examinemos la cuestión. Acudir a la memoria infantil plantea el problema de sus imprecisiones y limitaciones. Desembarazarse de esos recuerdos, sin embargo, anularía el aval como testigo de la Historia que, precisamente, concede la legitimidad para narrarla. Mantenerlos, entonces, acarrea el esfuerzo de encontrar una vía literaria que salve la distancia entre las carencias del conocimiento del nińo sobre los hechos recordados y el conocimiento superior que el adulto ha podido reunir, a posteriori, a partir de sus propias investigaciones. La solución sería la integración de la doble línea que señala Durán López.

El balcón, otra forma de la ventana, es la solución que tantea Mesonero, útil en tanto que, como espacio liminar que por ser una abertura separa y comunica a un tiempo los dos elementos de una dualidad (lo privado y lo público, el hogar y la calle), repite la dualidad metodológica que debe afrontar: unir la escritura del recuerdo infantil a la escritura del conocimiento del adulto. Se trata de dos escrituras tan distintas que la fusión armónica de ambas exige una pirueta un tanto forzada. El humor que adereza el costurón es en nuestra opinión una señal del consciente grado de trabajo experimental intrínseco a la resolución de este autoimpuesto desafío. Veamos esa huella quirúrgica en el texto: «Y en tanto que el niño duerme el sueño de la inocencia, aprovecha el hombre su silencio para trazar en algún modo el episodio local de aquel célebre motín, con todos los pormenores» ${ }^{6}$. Es decir, después de que el niño haya contemplado desde el balcón, como si de

5. F. Durán López, «Las Memorias de un setentón de Mesonero Romanos en el marco de la autobiografía española decimonónica», Anales de Literatura Española, 14, 2001, p. 68.

6. R. de Mesonero Romanos, Memorias de un setentón, natural y vecino de Madrid, Madrid, Oficinas de la Ilustración Española y Americana, 1880, 17. 
un emocionante acontecimiento lúdico se tratara, los hechos históricos, el narrador adulto hace callar al niño, al recuerdo de la infancia, e introduce su voz, la yuxtapone, mejor. El funcionamiento del balcón ha sido doble. Por un lado, literalmente, ha permitido poner en contacto el mundo sin historia del nińo, con la Historia: el adentro (la casa) y el afuera (la calle, la ciudad); pero, además, la acción del balcón como abertura, vía de contacto de mundos diferentes, se prolonga literariamente, figurativamente, en el ejemplo citado. En efecto, el escritor se desdobla y se retrata a sí mismo dormido; mejor: se asoma como narrador adulto a la recreación de sí mismo como nińo dormido. Juego de dobles, por tanto, que el humor, la ligereza de la escritura comunica: es el balcón, ese humor, el que permite el juego del desdoblamiento y, de paso, disimular la fractura del no saber (la «inocencia» del niño, en sentido etimológico, incluso) y el saber (los "pormenores», tan propios de la técnica del cuadro de costumbres que diera fama a Mesonero). El balcón instaura una dialéctica de espacios y tiempos con un marcado carácter visual. Es el ver desde el balcón o la ventana lo que le convierte en un cronotopo notable, en tanto que, como hemos visto, permite convivir, por arte de mágico e imaginativo birlibirloque, tiempos distantes, saberes, formas heterogéneas de estar en el mundo pero que al comunicarse dan el efecto de coherencia que la escritura autobiográfica persigue. La dialéctica de la ventana instaura un juego de miradas que se inscriben en el propio juego de miradas que es la escritura autobiográfica. Así, por seguir con el ejemplo de Mesonero, la Historia es vista a través del balcón por el niño Ramón y, a su vez, el niño Ramón es «visto», leído, recordado, por el adulto Mesonero, cuyo recuerdo, por seguir la propuesta de «mise en abîme» que sugiere la dialéctica de la ventana, es leído, visto, contemplado por el lector que se «asoma» al texto.

La dialéctica de la ventana se instala, entonces, en la escritura autobiográfica en toda su amplitud en tanto que cifra de su esencial carácter dialéctico, fantasmagórico y, literalmente, espectacular. La autobiografía puede ser entonces la dialéctica de la voz que recuerda y del ser que es recordado; la dialéctica de la realidad, desaparecida en el pasado, y la palabra que la rescata a la actualidad del lector y le da la vida de nuevo, pero como un fantasma; la dialéctica, en fin, del narrador que se hace actor de sí mismo y el lector que debe juzgar la representación, creer el diálogo que se le recita como líneas de vida. En otras palabras, trazamos aquí a través del uso de las ventanas en la autobiografía una concepción dinámica que incluye en un único mecanismo la consideración de la autobiografía como prosopopeya que hace hablar 
al ser del pasado ${ }^{7}$, como presencia, por tanto, de una ausencia ${ }^{8}$ y como un acto performativo que no es sino, como intervención con voluntad de repercusión pública, un gesto ético frente al otro.

Este complejo trabajo de las ventanas lo ilustra muy bien el segundo libro de La arboleda perdida (1959), de Rafael Alberti. Como es sabido, esta segunda entrega ya no consiste en el lamento por la pérdida de la patria ideal, ligada a la infancia gaditana, como sucede en la primera entrega de la Arboleda, sino en el relato, al modo de un bildungsroman, de la formación del artista, con un tono que une tanto la nostalgia como el fervoroso retrato de una generación y un proceso de renovación cultural en marcha a lo largo de las décadas de 1920 y 1930.

En el proyecto autobiográfico de Alberti la ventana aparece como el lugar para anunciar la profecía de su propio destino, puntualmente cumplida al final del libro. Se trata de un movimiento teleológico retrospectivo, muy característico de la autobiografía, que dota de coherencia a la narración de la propia vida mediante la identificación en el pasado de la semilla que va a dar su fruto. Comprobemos lo expuesto en este fragmento localizado en las primeras páginas de este segundo libro de La arboleda:

Jamás olvidaré mi leonera, mi cuarto encantador [...] ¡Cuántos amaneceres penetraron por su ventana! [...] Pero no sólo fueron las albas despaciosas las que se entraron siempre en él, iluminándome de rosa la almohada, los libros, mi tablero de dibujante o mi caballetito de pintor. También un día estuvo abierta su ventana para los ecos de la muerte. El tableteo veloz de unas ametralladoras me sobresaltó el sopor de una siesta de agosto. Venía de Cuatro Caminos, la barriada obrera del oeste madrileño. Yo entonces nada sabía de huelgas, nada comprendía de los justos derechos a la vida de esos hombres llamados proletarios ${ }^{9}$.

Resulta curioso comprobar cómo, al igual que en el cuadro de Vermeer que recordábamos al principio, el mundo exterior penetra más como una premonición (luz, eco) que como una patente realidad. El mundo para este joven sin oficio es aún un terreno no decidido, ni definido: el mundo exterior es aún la ensoñación difusa de un conjunto de opciones todavía abiertas,

7. Véase al respecto P. de Man, «Autobiography as Defacement», Modern Languages Notes, 94, 1979, 919-930.

8. Véase G. Agamben, Stanzas: word and fantasm in western culture, Minneapolis, University of Minnesota Press, 1993.

9. R. Alberti, La arboleda perdida, 1. Primero y Segundo libros (1902-1931), Madrid, Alianza Editorial, 1998, p. 124. 
no resueltas aún; es decir, no concretadas o, mejor, no constreñidas a una decisión, a un único camino. ¿Cuál de todas las sugerencias será la decisiva? El narrador adulto se encarga de seńalarlo sutilmente cuando corrige, como hacía Mesonero, por otro lado, su no saber juvenil con el saber del adulto: los justos derechos de los proletarios. Justos derechos que adoptará como suyos cuando al final del libro la imagen definitiva del joven que opta al arte sea la del poeta en la calle, políticamente comprometido. Desde el final del libro comprendemos. El ardid de la ventana es sumamente efectivo: como terreno liminar y aún mágico, como «nexo entre dos situaciones narrativas distintas» ${ }^{10}$, permite al joven atisbar el futuro y permite al adulto atisbar al joven que fue, introduciéndose de rondón en la escena mediante el comentario de lo visto a través de la ventana. El desdoblamiento de interior y exterior se ha convertido, por extensión del juego de la ventana, en el desdoblamiento que articula la escritura autobiográfica entre el ser recordado y el ser que recuerda. De paso, el narrador en su intromisión carga la suerte en torno a ese eco que hace surgir del otro lado de la ventana. Desde ese momento, ese eco se reviste de un sentido muy especial; un sentido que nos hace entender, en palabras de Jean Starobinsky, cómo «the window is the frame, at once near and distant, in which desire waits for the epiphany of its object» ${ }^{11}$. En efecto, la ventana es el lugar del deseo, del deseo de ser como respuesta, por otro lado, a la "carencia de ser», que afecta a Alberti en $L a$ arboleda, como ya señalara Randolph D. Pope ${ }^{12}$.

En definitiva, cuando Alberti, alquimista de las palabras, convierta el eco en la realidad de los enfebrecidos años y días inmediatos a la proclamación de la Segunda República en Madrid, habrá dado forma a la epifanía. La autobiografía permite así este interesante, lícito o no, juego de control sobre la propia vida, cuyo resultado es el ofrecerse a sí mismo, con la fuerza de una revelación, enmascarado bajo la apariencia de un destino por inevitable, necesario. En estas líneas podemos ver la epifanía y su puesta en práctica:

El grito y la protesta que de manera oscura me mordían rebotando en mis propias paredes, encontraban por fin una puerta

10. M. Teresa Zubiaurre, El espacio en la novela realista. Paisajes, miniaturas, perspectivas, México, Fondo de Cultura Económica, 2000, p. 37.

11. J. Starobinski, «Windows: from Rousseau to Baudelaire», The Hudson Review, 40.4, $1988,551$.

12. Véase R. D. Pope, "La autobiografía del exilio: el ser previamente preocupado de Rafael Alberti y María Teresa León», El exilio de las Españas de 1939 en las Américas: “¿Adónde fue la canción?», coord. José María Naharro-Calderón, Barcelona, Editorial Anthropos, 1991, 369-378. 
de escape, precipitándose, encendidos, en las calles enfebrecidas de estudiantes, en las barricadas de los paseos, frente a los caballos de la guardia civil y los disparos de los máusers. Nadie me había llamado. Mi ciego impulso me guiaba ${ }^{13}$.

Una abertura (atención: una puerta, no una ventana esta vez) une el espacio interior y la calle para cobrar en ésta la identidad. Sonidos y colores juegan a las correspondencias para establecer los lazos; lazos hechos de la intangible materia de la luz, el sonido (y las palabras), pero no por ello menos efectivos, poderosos. Así, el grito y la protesta individual de la grave crisis personal de los ańos de alrededor de 1928 y la redacción de Sobre los ángeles se transmutan en los gritos colectivos frente a las fuerzas del orden represoras. El negro ánimo, simbolizado en el negro interior de una casa, metáfora antigua para el alma, los adentros psicológicos, como se prefiera, se transmutan en la luz, nueva luz, que guía a obreros y estudiantes. El lirismo, la visión idílica, las metáforas exaltadas corresponden a la epifanía del deseo de la que hablaba Starobinsky, del mismo modo que nos sitúan delante de la evidencia puramente literaria de la identidad en la autobiografía. Y todo ello a través de la puerta construida con palabras, metafórica salida a cuyo través se transmutan mágicamente materiales obsoletos en una nueva construcción. Puerta, en efecto, y no ventana esta vez, porque la ventana es el espacio del deseo y la puerta aquel por el que se accede a la realidad revelada de su objeto. Un tránsito éste, por decirlo al modo de Cernuda, del deseo a la realidad que no siempre es tan fácil como lo parece para Alberti. El mismo Cernuda y muchas escritoras, las recordadas por Gaite y ella misma, han pasado mucho tiempo al lado de la ventana, forjando el sueño de su identidad y esperando o luchando por ganar la puerta que dé salida al cumplimiento del deseo. Pero no dejemos aún el valor de la puerta. Como realización del deseo de la identidad, la puerta completa el valor de la ventana dentro de la estructura del juego de la autobiografía: es la ventana que puede franquearse. Del mismo modo, el libro es la ventana por la que, al abrirla el lector, el espacio de lo imaginario, allí donde el autobiógrafo sueña consigo mismo, entra en la realidad: es la mercancía que puesta en circulación apuesta por participar en el espacio social en nombre de su autor, en lugar del autor, gracias al lector. He aquí, en este intercambio entre lector y autobiógrafo, asomándose el uno al otro, mutuamente, donde surge ese elemento ético que ha señalado Loureiro como esencial en la escritura autobiográfica:

13. Alberti, op. cit., p. 306. 
The ethical structure of address inherent to autobiography as saying guarantees that autobiography is never a fiction [...]. At any rate, the writer's illusion about referenciality should not become the critic's delusion. The past cannot be reproduced by means of language, but the constitutive alterity of the subject requires that it respond to the other, and in autobiographical writing that response cannot be measured in terms of truth or mimetic restoration because as ethical gesture it remains outside the domain of thematics and epistemology 14 .

En efecto, la autobiografía no es ficción: es el espacio liminar, como la ventana, en el que la escritura del deseo y la intervención pública, política también, se comunican indesligablemente. La autobiografía es, entonces, el espacio, realmente existente, del tránsito, de la apertura del deseo como tal sobre la realidad, con necesidad de intervenir como tal sobre la realidad. Como muchos autobiógrafos han experimentado junto a la ventana, la autobiografía ofrece las promesas del deseo (una identidad a medida, si se quiere) y la ventaja de no concretarse nunca, de no tener más cuerpo que las palabras, que la luz del cuadro de Vermeer. Pero la luz no es menos real aunque no pueda contenerse en las manos, del mismo modo que la personalidad que pone en juego es tan intangible como las palabras y tan real como la propia materialidad del volumen.

Echar un vistazo a las coordenadas temporales en que se ubica la escritura y aparición del libro da buena idea de la confianza en la efectividad de esa escritura del deseo cuando circula públicamente. Recordemos, por seguir con el ejemplo de Alberti un poco más, que ese segundo libro de su Arboleda aparece en Argentina, ya avanzado el exilio: cuando busca, a la altura de 1954 asentar en el otro lado de su Atlántico gaditano la imagen de un artista. Nada mejor que contar la historia de su formación en España como paralelo a su búsqueda y defensa de un lugar en la esfera artística argentina. Se trata de algo así como un segundo nacimiento al mundo del arte repitiendo el primero, mostrándolo al público a través de la ventana del libro: así como el joven, así el adulto, parece querernos decir Alberti. Mediante esta repetición cumple la autobiografía, por cierto, el trabajo de la memoria, según la considera Giorgio Agamben, en tanto que proceso de apertura de las posibilidades del pasado. Así describe ese mecanismo el filósofo italiano:

Repetition restores the possibility of what was, renders it possible anew; it's almost a paradox. To repeat something is making it possible

14. Loureiro, op. cit., p. 20. 
anew. Here lies the proximity of repetition and memory. Memory cannot give us back what was, as such: that would be hell. Instead memory restores possibility to the past. [...] Memory is, so to speak, the organ's of reality modalization; it is that which can transform the real into the possible and the possible into the real ${ }^{15}$.

La transformación de lo real en posible y de lo posible en real de la que habla Agamben no es sino el proceso de creación de la identidad que lleva a cabo Alberti en La arboleda, tal como la hemos estudiado: la creación y el autocumplimiento de una promesa. La nueva posibilidad del pasado cumplida en la promesa apunta definitivamente hacia el futuro, en Alberti de forma muy precisa. Pensamos en esa posibilidad como un papel público en un espacio concreto; no sólo un reclamar quién se ha sido contra el olvido, sino proclamar la energía creadora de quien aún tiene mucho que escribir. Esta trascendencia de la autobiografía la resume Paul John Eakin cuando escribe: «La creación de ficciones acerca del yo -en verdad la creación de un yo ficticio- es un hecho, y muy posiblemente, un hecho primordial de la experiencia, no simplemente en la creación autobiográfica, sino también en la construcción de una vida» ${ }^{16}$.

En Mesonero Romanos o Alberti al otro lado de la ventana se revela el objeto del deseo como exacta correlación de ese deseo. La identidad elaborada en el texto queda así fundada con rotundidad. En otros casos, sin embargo, la epifanía de ese objeto no ha quedado a la altura del deseo mismo. Entonces la ventana ya no es el espacio del tránsito o el espacio a cuyo través la visión (la ocular y la imaginativa) reconoce lo buscado; la ventana es entonces la barrera (el cristal) que deja entrever pero que no se atraviesa. El resultado es una identidad quebrada, incompleta o, mejor, dividida por la doble consideración de la identidad propia como carencia y como deseo de suplirla para lograr una síntesis satisfactoria del yo. Luis Cernuda ofrece en Ocnos (1942), sobre todo en esta primera edición, un ejemplo profundo y desgarrado.

Las coordenadas del deseo cernudiano en Ocnos son las del exilio (geográfico y existencial), el recuerdo de espacios interiores (casas, jardines) pertenecientes a la infancia sevillana y la localización en la frontera de esos espacios de la vivencia del deseo como sueño y frustración. De este modo podemos leer este fragmento de "Jardín antiguo», uno de los poemas iniciales de esta colección:

15. G. Agamben, «Difference and Repetition: On Guy Debord's Films», Guy Debord and the Situationist International, ed. Tom MacDonough, Cambridge MIT Press, 2002, 316.

16. P. J. Eakin, En contacto con el mundo, Málaga, Megazul-Endymion, 1994, 81. 
Allí en aquel jardín, sentado al borde de una fuente, soñaste un día la vida como embeleso inagotable. [...] Más tarde habías de comprender que ni la acción ni el goce podrías vivirlos con la perfección que tenían en tus sueños al borde de la fuente. Y el día que comprendiste esa triste verdad, aunque estabas lejos y en tierra extraña, deseaste volver a aquel jardín y sentarte de nuevo al borde de la fuente, para sońar otra vez la juventud pasada ${ }^{17}$.

No encontramos aquí la ventana, pero sí un espacio igual de mágico y con más antigua tradición: la fuente. Aunque el agua cristalina y el asomarse a ella rápidamente podrían equiparar la fuente a la ventana a cuyo través se sueńa la identidad. En todo caso, nos interesa llamar la atención acerca de cómo lo nostálgicamente añorado es el sueño mismo de la vida y no el contenido de los años vividos. El deseo del exiliado es volver a desear como entonces: soñar con soñar («otra vez» escribe el poeta). Ocnos es ese soñar otra vez, pero desde la conciencia, tan romántica, de la "caída en el mundo", como podemos leer en el último fragmento de la colección «Escrito en el agua». Se sueńa entonces sabiendo la imposibilidad de volver al borde de la fuente, al interior del jardín, al interior del pasado personal en el que la vida aún no era más que posibilidad gozosa y no una sistemática serie de frustraciones. Encontramos aquí una ruptura fundamental que impide la reconstrucción de una identidad al modo axiomático que propone Alberti, por ejemplo. Cernuda, a cambio, quiere regresar a esas habitaciones de donde otros han podido o querido salir, pero tendrá que conformarse con soñar el sueño, con la palabra como signo de la carencia y no como triunfo de la creación. Así, a Cernuda no le interesa la historia, con mayúsculas o no, como el espacio y el tiempo donde validar una identidad y usarla. Cernuda entiende la historia como un espacio en el que no puede entrar con una identidad definida, sino radicalmente cuestionada. De esa inadecuación entre el tiempo previo a la historia (la infancia recordada como fuera del tiempo) y la caída forzada en aquella surge la nostalgia por un pasado cuya perfección es, a su vez, la idealizada respuesta a la imperfección de la historia. Se trata de una nostalgia, además, fundamentalmente teñida por la conciencia, producto de la inserción en la historia y en el tiempo, de la imposibilidad de reinstaurar la adecuación entre vida y tiempo si no es como deseo y aún más exactamente como carencia del objeto de ese deseo.

La ventana es el espacio al borde del tiempo, la frontera entre la casa de la infancia atemporal y la calle donde se desarrolla la historia y la vida

17. L. Cernuda, Ocnos, Londres, The Dolphin, 1942. 
(ansiada y temida por igual). Este punto de partida no es extraño a los textos autobiográficos que hemos recorrido aquí. La diferencia en Cernuda es la conciencia de las distancias que une y separa la ventana. Frente a la transparencia de la ventana en Mesonero y Alberti, el cristal de la ventana cernudiana permite ver, sí, pero es una fría frontera también, símbolo de la imposibilidad de hallar el paso, el más allá. Para visitar esta peculiar dinámica de la ventana copiamos a continuación este fragmento de Ocnos, parte final de «Pregones»:

El tercer pregón era al anochecer en otoño. [...] Tras el visillo del balcón, la frente apoyada al frío del cristal, miraba el niño la calle un momento, esperando. Entonces surgía la voz del vendedor viejo, llenando el anochecer con su pregón ronco de «Alhucema fresca!» [...] Se le adivinaba más que se le veía, tirando de una pierna a rastras, nebulosa y aborrascada la cara bajo el ala del sombrero caído sobre él como una teja, que iba, con su saco de alhucema al hombro, a cerrar el ciclo del año y de la vida.

Era el primer pregón la voz, la voz pura; el segundo el canto, la melodía; el tercero el recuerdo y el eco, la voz y la melodía ya desvanecidas. (p. 14)

El poema en prosa al que pertenece la cita está dedicado al recuerdo de tres pregones oídos por el niño en diversas etapas del año. Se trata de voces que anuncian ciertas mercancías pero que a través de la escritura cernudiana de ese recuerdo se convierten en cifra de una manera de estar y entender la vida.

En el recuerdo de este tercer pregón se superpone a la experiencia del nińo la valoración del adulto. Una vez más aparece el desdoblamiento que propicia la ventana: al nińo que mira por ella se le superpone la voz del adulto que se mira a sí mismo mirando al exterior y define el contenido de esa mirada. El sonido de la historia oído en Mesonero o Alberti promete entrar en la Historia, lo que efectivamente ocurre cuando el autobiógrafo transforma ese sonido en palabra y forja con ella, trabajada artísticamente, la identidad como gesto ético. En Cernuda el cristal frío separa de esa promesa al niño que espera. Así cabe entender la dialéctica del frío y la frescura, la vida, contenida en la alhucema pregonada. En Alberti la palabra acude a la ventana como el vehículo del deseo para conectar el interior con el objeto del deseo ansiado. En Cernuda la palabra no es apertura al futuro como lo es en Alberti. En Cernuda la palabra no es transparente: primero vida y luego recuerdo, vida literaturizada, literatura en fin; en Cernuda la palabra se convierte de inmediato en recuerdo sin que la vida haya tenido lugar. La 
palabra es tan sólo palabra: hermosa, evocadora, sí, pero no trascendente, no el pie de una línea narrativa que dé coherencia, que cree la identidad del poeta como sucede en Alberti, a toro pasado, si se quiere. "Alhucema», el aromático espliego, se convierte en una palabra intransitiva, que no predica nada del autor, sino la belleza de sí misma, exótica, arcaizante, oriental. Este escamoteo de la vida deja en pie, sin embargo, la palabra oída desde el borde de la vida como único resto de una promesa imposible, como presencia de una ausencia que se ha producido antes de ser siquiera presencia real alguna vez. La sustancia del recuerdo permanece con la intangibilidad de la luz o el perfume en el propio disolverse del recuerdo, en su «desvanecerse», al decir del texto. El recuerdo se transforma en el deseo de su propia sustancia: queda convertido en un fantasma que la palabra del poeta recupera al recuperar el recuerdo. Si así dota a esa palabra de trascendencia en cuanto a la exposición de una identidad en el texto autobiográfico es de forma negativa. La palabra en Cernuda no garantiza la identidad, la diluye incluso, a diferencia de Alberti, una vez más, en el que la palabra, derivada del eco asegura el cumplimiento de la identidad. Compárese a este respecto el citado fragmento de "Pregones» con "Escrito en el agua», el final de Ocnos en su versión de 1942. Como un eco este último del anterior, el contenido del recuerdo infantil se convierte en el contenido de la identidad escindida, desvanecida, fantasmal, desde la que se escribe el libro. Así, las últimas líneas de Ocnos son como sigue:

Y si Dios no existe, ¿̇cómo puedo existir yo? Yo no existo ni aún ahora, que como una sombra me arrastro entre el delirio de sombras, respirando estas palabras desalentadas, testimonio (¿de quién y para quién?) absurdo de mi existencia. (p. 44)

El eco de la voz «desvanecida» en la palabra «desalentada» cierra la unidad de la primera edición de Ocnos y duplica, prolonga el proceso de la mirada a través de la ventana recordada, de modo que lo que mira el niño, la vida desvanecida en la palabra, es lo que encuentra al mirar sobre sí mismo el poeta en las coordenadas espacio-temporales que delimitan el proceso de la escritura: entre 1940 y 1942, exiliado en Glasgow, Escocia, tras la guerra civil, durante la segunda guerra mundial.

La ventana, el cristal, filtra la vida y la identidad del poeta: la deja reducida a su esencial carencia: ser tan sólo palabra. He aquí, a través de la distancia inserta en el uso de la imagen de la ventana, una interesante reflexión sobre el sentido de una literatura del recuerdo, convertida, al menos para Cernuda, en palabra que no restaura, sino que vuelve sobre sí misma, en 
tanto que palabra que apenas si es recuerdo, nunca la vida misma (nunca podría serlo, por otro lado) o tan siquiera su trascripción. Desmiente, a su modo, Cernuda el juego de birlibirloque de la autobiografía. Así, allí donde para los otros se crea la certidumbre de una identidad, el objeto, la misión en la vida avistada a través de la ventana por medio de la palabra (no lo olvidemos), Cernuda sitúa la advertencia sobre los límites de la capacidad creadora de la palabra del mismo modo como señala los límites de la vida en tanto que es vista como frustración del deseo (tan desmesurada ésta como, en correspondencia, lo es el otro). Queda la palabra, naturalmente, queda ese «desear volver»: un viaje que la lucidez, si se puede decir así, de Cernuda confina a los límites de lo que puede lograr la palabra; es decir: belleza, pero no el juego de ilusionismo con el que otros se acercan, como hemos visto, a la escritura autobiográfica.

En las autobiografías escritas por mujeres la ventana aparece, al igual que en Ocnos, como el lugar de la conciencia de la dificultad de acceder a un espacio público donde desarrollar una identidad plena. El cuarto de atrás (1978), de Carmen Martín Gaite es un ejemplo al respecto, pero también lo es, de una forma distinta a Cernuda, de la tematización de los mecanismos de la autobiografía alrededor de la imagen de la ventana. Lo podemos comprobar a partir del siguiente fragmento, en el que ventanas, memoria y miradas convergen de forma sorprendente y sutil:

Hace tiempo que no pasaba por la calle Mayor, se lo dije a mi amigo la otra tarde, allí parados delante de los balcones del número catorce, y luego, cuando echamos a andar nuevamente, sentí que rompía los hilos que me relacionaban con la vieja fachada: de pronto éramos ya una pareja anónima caminando por una calle anónima, me puse a contarle historias de aquel tiempo en que visitaba la capital [...]. Nos metimos por uno de los arcos que desembocan en la plaza Mayor [...]. Estaba anocheciendo y me pareció que había traspuesto una raya, a partir de la cual el mundo se volvía misterioso, una zona donde cabía lo imprevisto y las personas atisbadas desde el balcón eran ya sombra que se pierde. «¿Adónde irá esa pareja?», y me puse a cantar, de buen humor, "voy a Cúnigan, Cúnigan, Cúnigan», mientras la decepción ensombrecía los ojos que nos decían adiós y percibía el frío del cristal contra mi frente, empinándose debajo del visillo recogido.

¡Esa niña, qué manía de ponerse a leer con la cara pegada al balcón! -se quejaba la abuela ${ }^{18}$.

18. C. Martín Gaite, El cuarto de atrás, Barcelona, Ediciones Destino, 2003, p. 77. 
Como es sabido, el punto de partida de El cuarto de atrás es el trabajo de la memoria sobre la larga posguerra espańola desatada, liberada por la muerte del general Franco en 1975. En este fragmento la narradora (identificable con la propia Martín Gaite) pasea en un tiempo, cercano al presente de la escritura, al encuentro del recuerdo lejano: la nińa que fue en los primeros cuarenta. Esa niña es la que lee en el balcón, la que invoca en su imaginación un mundo que no existe. "Cúnigan» es el lugar que, como se explica en páginas anteriores, la nińa Carmen y una amiga suya han inventado como terreno para la felicidad, la fantasía y la huida de la miseria cotidiana.

La ventana es aquí tanto el lugar desde donde la niña desearía compartir con los amantes su misterioso destino como es al mismo tiempo la barrera cuyo carácter represivo se ve subrayado por el frío del cristal. La dialéctica de interior y exterior es una dialéctica de deseo y frustración, libertad y represión, ligada a la situación social de la mujer. No en vano, en cuanto a la división de la vida entre lo público y lo privado en la tradición cultural española, Martín Gaite nos ha recordado esta ilustrativa frase de Fray Luis de León: «como los hombres son para lo público, así las mujeres para el encerramiento» ${ }^{19}$. Pero hay más en ese fragmento de El cuarto de atrás si se lee con atención. La línea mágica que atraviesa la narradora en su viaje por Madrid es la línea del tiempo y el espacio. Una línea mágica que le permite el desdoblamiento y ser a un tiempo niña y adulta, mirándose una a la otra a través del tiempo y el espacio, coincidiendo en un mismo tiempo y espacio imposible, hecho por la superposición de miradas y palabras. En efecto: reparemos en la pareja que pasea por Madrid y la pareja que ve la niña recordada. ¿Acaso no son la misma? A un lado y otro del balcón la Carmen adulta y la Carmen nińa se miran. El desdoblamiento que genera la ventana en otras obras opta aquí a fondo por sus implicaciones fantásticas, en consonancia, por otro lado, con el carácter experimental de la novela. Veamos el cambio de punto de vista de esa extraña frase: «la decepción ensombrecía los ojos que nos decían adiós y percibía el frío del cristal contra mi frente». ¿A quiénes dicen adiós los ojos? ¿Quién siente el frío del cristal? Parece como si a un tiempo la narradora se desdobla en el nosotros de la pareja que ve en una ventana a una niña triste (por no poder acompañarles, por ejemplo) y en la niña que ve a esa pareja caminar. Los puntos de vista se superponen a través del espacio mágico de la ventana a la que se asoman pasado y presente. Quizá así se entiende por qué la narradora afirma «rompí los hilos que me relacionaban con la vieja fachada: de pronto éramos ya una pareja anónima caminando por una calle anónima».

19. C. Martín Gaite, Desde la ventana, ed. cit., p. 35. 
Sí, la pareja vista por la niña se ha hecho adulta, se ha independizado del contenido del recuerdo infantil. El recuerdo, la mirada sobre el pasado, liga y separa, (como la ventana, como la escritura autobiográfica): hace tomar conciencia de la separación, objetivando el recuerdo, convirtiéndolo en materia narrada, separada, desplazada en el juego de los desdoblamientos, que no es, dicho juego, sino las formas del desplazamiento de la palabra y de la operación del recuerdo.

El juego de la ventana se lleva aquí hasta sus últimas consecuencias: el uso consciente del juego de los desdoblamientos pone al lector ante el vértigo de la mise en abîme que implica también el juego de las ventanas. Se trata del juego del lector que se asoma a un narrador que se asoma a un ser del pasado que se asoma a la calle, etc. Y dentro del juego cabe añadir aún un detalle más: la frontera de la frontera, la superficie del cristal. Volvemos ahora sobre las manchas de las manos de la niña que tanto enfadan a la abuela. Acaso podrían entenderse esas huellas como el correlato de las huellas sobre la superficie blanca del papel. Se completaría así el juego de la ventana. Las huellas rebeldes que deja la nińa son las palabras que lee el lector, palabras liberadoras de la memoria de un tiempo de represión; y el libro que lee la nińa junto a la ventana es la trasposición de la autora que lee su pasado a través de las ventanas y del libro que lee el lector asomado al mundo de la creación literaria.

El complejo juego de las miradas a través de la ventana, de su cristal, separa la autobiografía de la novela, al menos de esa forma de entender la novela como espejo stendhaliano. Así, la autobiografía no puede ser un espejo aunque de ella emerja un retrato del autobiografiado. En todo caso, como precisamente parece advertir la propia Martín Gaite en la dedicatoria a Lewis Carroll que encabeza El cuarto de atrás, si la escritura del pasado se parece al espejo de Alicia es en cuanto a la habilidad de la primera para el desdoblamiento, para ser el pasaje mágico a otros lugares y tiempos. Y si es admisible aceptar que sea la ventana en la autobiografía espejo mágico, más factible será considerarla, como corolario del sistema de miradas que suscita, teatro. En efecto, la organización espacial que la ventana suscita evoca en seguida la situación teatral. Así lo entendía Greer Cohn, a propósito de Mallarmé:

The window is a small theater -the place of encounter of all outdoors and the most intimate interior life, of the high and the low and so forth- and that the curtains are easily assimilated to 
this image. An actor, dramatically, emerges from between theater curtains as if born: he appears, a phenomenon ${ }^{20}$.

Esta consideración de la ventana se ajusta al dialogismo, en el sentido bajtiniano, de la autobiografía, entendido este aquí en tanto que el sentido ético y performativo de la escritura autobiográfica. El retrato del autobiografiado, el «aparecer» del que habla Greer Cohn es el resultado de un proceso dinámico, estratégico, teatral, de nuevo, y no un simple reflejo mimético, estático, propio del espejo. En El cuarto de atrás ese dialogismo es explícito, puesto que el recuerdo, la escritura misma, nacen como resultado de la conversación de la narradora con un misterioso señor de negro que inesperadamente ha acudido a visitarla. En un determinado momento, como resultado del juego metaficcional que recorre la obra, la narradora es consciente de la teatralidad de dicho diálogo:

Me acerco a la puerta, sin hacer ruido, y asomo un poquito la cabeza, amparándome en la cortina, como si observara entre bastidores, el escenario donde me va a tocar actuar en seguida. Ya lo conozco, es el de antes, veo la mesa con el montón de folios debajo del sombrero -evidentemente el tramoyista ha añadido algunos más- y al fondo, a través del hueco del lateral derecha (suponiendo que el patio de butacas estuviera emplazado en la terraza), vislumbro las baldosas blancas y negras del pasillo que conduce al interior de la casa; el hueco está cubierto a medias por una cortina roja del mismo terciopelo que la que me esconde [...], no da la impresión de que por ese lateral vaya a aparecer ningún actor nuevo. El personaje vestido de negro ya está preparado, espera tranquilamente mi salida sentado en el sofá, todo hace sospechar que vamos a continuar la representación mano a mano ${ }^{21}$.

La narradora parece acordarse aquí de la paradoja del comediante de la que hablara Denis Diderot ${ }^{22}$, porque en efecto, el actor y el autor de la comedia coinciden, para mayor ambigüedad de la representación. «Yo soy el que digo que soy yo", afirma el autobiógrafo aupado en el escenario. Los espectadores, al otro lado, en el patio de butacas, fuera en la terraza, en el caso de El cuarto de atrás, separada ésta del interior por una ventana-puerta; los espectadores, decimos, deben creer al actor, juzgarle, rechazar el juego o tomarlo de forma literal. Surge aquí la máscara, intermediaria de la verdad o

20. R. Greer Cohn, «Mallarme’s Windows», Yale French Studies, 54, 1977, p. 29.

21. C. Martín Gaite, El cuarto de atrás, ed. cit., p. 151.

22. Véase D. Diderot, Paradoxe sur le comédien, Paris, Armand Colin Éditeur, 1992. 
mentira interesada: la máscara del artista revolucionario que tan hábilmente ostentaba Alberti, por ejemplo, recordémoslo, con una sinceridad de la que no tenemos por qué dudar (otra cosa es el contenido del gesto). Surge aquí el fantasma: un ente que habla en nombre de otro, desplazado por el lenguaje, por el juego teatral, a un lugar fuera de la escena, un lugar indeterminable porque sólo a la luz de la literatura, de la representación puede aparecer. El autobiógrafo es así ese fenómeno, más allá del sentido etimológico de la propia palabra, que en español apunta hacia lo asombroso, lo sobrenatural. El coherente encaje de esta exploración autobiográfica en el interior de un texto que aboga por el cruce de géneros, por la literatura fantástica, en especial, no hace sino revelar las posibilidades literarias latentes en la autobiografía, tan ligada, aparentemente, al discurso historicista, realista.

Martín Gaite y Cernuda se sitúan frente a la autobiografía en posiciones cercanas. Pero si para Gaite este gesticular sin ataduras es una forma de liberar un tiempo atado (el de la posguerra), para Cernuda es una forma de perderse, al no sentirse la atadura de lo real con el gesto. Si dar cuenta de sí es perderse para Cernuda, para Gaite es ganarse en los otros, los lectores, el público, la sociedad que dota de sentido al gesto autobiográfico.

Máscara, teatro entonces, cronotopo que concita, convoca, mágicamente, espacios y tiempos diversos... la ventana es un haz de diferentes elementos, de planos superpuestos de significación, de metáforas, de imágenes, como se prefiera, indesligable del desarrollo de un modo de explorar la intimidad propio de la modernidad. Y una exploración pictórica o escrita, artística en definitiva, que es, al mismo tiempo, uno de los rasgos que definen la modernidad. Esto es así al menos en cuanto la luz a través de las ventanas de los cuadros de Vermeer de Delft o las estrategias de la escritura de la memoria que hemos descrito en estas páginas constituyen la paradójica manifestación de la fragilidad y las posibilidades inacabables de la creación de la identidad como una forma activa de intervención social que rebasa los límites del narcisismo o lo dota de su verdadero sentido. Así, esclarecedora como la luz e intangible, la escritura autobiográfica. 